\title{
Control beliefs and risk for 4-year mortality in older adults: a prospective cohort study
}

Wei Duan-Porter ${ }^{1 *}$, Susan Nicole Hastings ${ }^{2,3,4,5}$, Brian Neelon ${ }^{6}$ and Courtney Harold Van Houtven $3,4,5$

\begin{abstract}
Background: Control beliefs are important psychological factors that likely contribute to heterogeneity in health outcomes for older adults. We evaluated whether control beliefs are associated with risk for 4-year mortality, after accounting for established "classic" biomedical risk factors. We also determined if an enhanced risk model with control beliefs improved identification of individuals with low vs. high mortality risk.

Methods: We used nationally representative data from the Health and Retirement Study (2006-2012) for adults 50 years or older in $2006(n=7313)$ or $2008(n=6301)$. We assessed baseline perceived global control (measured as 2 dimensions - "constraints" and "mastery"), and health-specific control. We also obtained baseline data for 12 established biomedical risk factors of 4-year mortality: age, sex, 4 medical conditions (diabetes mellitus, cancer, lung disease and heart failure), body mass index less than $25 \mathrm{~kg} / \mathrm{m}^{2}$, smoking, and 4 functional difficulties (with bathing, managing finances, walking several blocks and pushing or pulling heavy objects). Deaths within 4 years of follow-up were determined through interviews with respondents' family and the National Death Index.

Results: After accounting for classic biomedical risk factors, perceived constraints were significantly associated with higher mortality risk (third quartile scores odds ratio [OR] 1.37, 95\% Cl 1.03-1.81; fourth quartile scores OR 1.45, 95\% $\mathrm{Cl}, 1.09-1.92)$, while health-specific control was significantly associated with lower risk (OR 0.69-0.78 for scores above first quartile). Higher perceived mastery scores were not consistently associated with decreased risk. The enhanced model with control beliefs found an additional 3.5\% of participants $(n=222)$ with low predicted risk of 4-year mortality (i.e., $4 \%$ or less); observed mortality for these individuals was $1.8 \%$ during follow-up. Compared with participants predicted to have low mortality risk only by the classic biomedical model, individuals identified by only the enhanced model were older, had higher educational status, higher income, and higher prevalence of diabetes mellitus and cancer.
\end{abstract}

Conclusion: Control beliefs were significantly associated with risk for 4-year mortality; accounting for these factors improved identification of low-risk individuals. More work is needed to determine how assessment of control beliefs could enable targeting of clinical interventions to support at-risk older adults.

Keywords: Control beliefs, Mortality risk, Biomedical predictors

\section{Background}

Aging is accompanied by increasing physical limitations, more chronic health conditions, and higher risk for mortality, but there is substantial variation in individual risk for these adverse health outcomes [1-4]. Furthermore, the relative importance of biomedical, psychological, and socioeconomic risk factors for predicting outcomes, such as mortality, remains unclear. Among psychological

\footnotetext{
* Correspondence: wei.duanporter@va.gov

${ }^{1}$ Minneapolis VA Health Services Research and Development, One Veterans

Dr, Minneapolis, MN 55417, USA

Full list of author information is available at the end of the article
}

factors thought to impact health, control beliefs have been highlighted as relevant for both health behaviors [5-7] and outcomes, including mortality [8-12].

Control beliefs refer to an individual's perception of his/her ability to impact life events, and range from global beliefs to situationally specific perceptions [8]. Differences in control beliefs likely reflect dispositional tendencies, along with lifetime disparities in socioeconomic factors and experiences of discrimination [8-11]. Among older adults, control beliefs may affect adoption of adaptive and healthy behaviors in the face of increasing 
physical and cognitive limitations [7]. Furthermore, control beliefs have been associated with ability to manage certain chronic health conditions [5, 6], which contribute to mortality risk. Finally, control beliefs are associated with general perceptions of well-being and such positive psychological perceptions may be associated with decreased activation of stress and inflammatory pathways, leading to improved long-term health $[6,7,12]$. Thus, control beliefs are informed by diverse psychosocial factors and may impact risk for mortality through a variety of behavioral and physiologic pathways.

Despite some previous work suggesting the importance of control beliefs for mortality [13-17], it remains unclear if these psychological perceptions would remain relevant for mortality risk when specific biomedical factors (e.g., health conditions and functional impairments $[3,18,19])$ are taken into account. Previous studies examining the association of control beliefs with mortality adjusted for general health status and/or count of chronic health problems, but did not consider the differential importance of individual conditions or impairments [13-17]. Understanding the relationship between control beliefs and mortality, while accounting for the differentials risks associated with various health conditions and impairments, may offer further insights into the relative importance of psychological vs. biomedical factors. Additionally, some groups did not consistently find significant associations between control beliefs and mortality risk when general health measures were included in modeling [13-16]. Thus, it remains to be seen whether control beliefs improve risk prediction when individual, well-established biomedical factors are included in statistical modeling.

We used survey data from a large nationally representative study of older Americans, in order to investigate whether control beliefs were significantly associated with 4-year mortality risk, after accounting for known "classic" biomedical risk factors [3]. Next, we determined if the addition of control belief variables improved predictive accuracy of our risk model. Finally, we evaluated how incorporation of control beliefs changed the classification of low vs. high-risk individuals.

\section{Methods}

\section{Study design and sample}

We used 2006-2012 data for Health and Retirement Study (HRS) participants aged 50 or older at baseline (in 2006 or 2008), with at least 4 years follow-up. HRS is an ongoing observational study of representative samples of middle-aged and older adults in the United States. Biennial surveys assessed a range of demographic, economic, and health-related topics, while psychosocial surveys were given every 4 years, providing information on personality traits, control beliefs, and social support, among other factors $[20,21]$. Psychosocial surveys were first given to a random $50 \%$ of participants in 2006, and to the other half first in 2008.

For determining whether control beliefs are associated with mortality risk, we used data for individuals with baseline health and psychosocial information in 2006 $(n=7313)$, called the "2006 cohort." To evaluate accuracy of risk models and compare low vs. high-risk classification, we selected individuals with baseline data in $2008 \quad(n=6301)$, called the "2008 cohort." Follow-up data were available for $98.6 \%$ and $97.6 \%$ of the 2006 and 2008 cohorts, respectively.

This study was approved by the Durham Veterans Affairs Medical Center Institutional Review Board.

\section{4-year mortality outcome}

We determined death by 2011 for the 2006 cohort, to account for the fact that some of the 2006 cohort were actually first interviewed in early 2007. Similarly, we assessed for death by 2013 for the 2008 cohort. Year of death was assessed by HRS exit interviews with respondents' family. HRS actively monitored and recorded participant deaths through the National Death Index and sought out interviews with surviving family and/or partners, resulting in a completion rate of $93 \%$ for exit interviews after deaths [22].

\section{Classic biomedical risk factors}

Using 1998-2002 HRS data for adults 50 and older, Lee et al. [3] developed and validated a multivariable logistic model for 4-year mortality. Logistic regression produces similar risk estimates as Cox proportional hazards modeling when few individuals would be censored and the outcome is relatively rare during follow-up [23]. Additionally, because logistic regression can be used to estimate risk for a given individual, it is very commonly employed to develop risk calculators for clinical settings [23, 24]. Lee et al. [3] intended to generate a model that would aid clinical risk stratification, as well as inform epidemiologic studies. They evaluated over 40 demographic, health and functional status variables, before selecting 12 risk factors: age, sex, 4 medical conditions (diabetes mellitus, cancer, lung disease and heart failure), body mass index (BMI) less than $25 \mathrm{~kg} / \mathrm{m}^{2}$, current smoking, and 4 functional difficulties (with bathing, managing finances, walking several blocks and pushing or pulling heavy objects). Although developed to predict risk of death within 4 years, this model also accurately predicted 10-year mortality [25].

\section{Control belief variables}

We assessed global control beliefs as two variables, perceived constraints and mastery, in addition to healthspecific control. Perceived constraints and mastery indicate perceived external restrictions and personal competence, respectively $[8,9,20]$. Perceived constraints 
scores were the mean of responses on a Likert scale ( $1=$ strongly disagree, $6=$ strongly agree) to 5 statements related to feelings of helplessness and lack of control: 1) "I often feel helpless in dealing with the problems of life;" 2) "Other people determine most of what I can and cannot do;" 3) "What happens in my life is often beyond my control;" 4) "I have little control over the things that happen to me;" and 5) "There is really no way I can solve the problems I have." Perceived mastery was the mean of responses to 5 statements indicating confidence in one's skills and ability to act: 1) "I can do just about anything I really set my mind to;" 2) "When I really want to do something, I usually find a way to succeed at it;" 3) "Whether or not I am able to get what I want is in my own hands;" 4) "What happens to me in the future mostly depends on me;" and 5) "I can do the things that I want to do." In support of the conceptualization of perceived constraints and mastery as two distinct dimensions, previous work has established that these items load onto two latent factors $[9,26]$. Cronbach alphas of 0.86 and 0.89 have been reported for the perceived constraints and mastery scales, respectively [27, 28]. Health-specific control was assessed with "Using a 0 to 10 scale where 0 means 'no control at all' and 10 means 'very much control', how would you rate the amount of control you have over your health these days?"

Because all control belief variables showed highly skewed distributions, we were concerned with possible nonlinear effects throughout the full range of scores. Thus, we categorized scores into quartiles to improve interpretation of associations between control beliefs and mortality risk.

\section{Covariates and descriptive characteristics}

Per Lee et al. [3], we categorized baseline age as 50-59 years, 5-year intervals for 60-84 years, and 85 and older. We also assessed sex, race, Hispanic ethnicity, marital status, education, total household income, and health insurance status.

We used responses to questions beginning with "Has a doctor ever told you that you have ..." for diabetes mellitus, hypertension, heart disease, heart failure, lung disease, cancer ("excluding minor skin cancer"), psychiatric problems and arthritis. We calculated BMI from measured height and weight, and per Lee et al. [3], we dichotomized BMI as less than $25 \mathrm{~kg} / \mathrm{m}^{2}$ or not. Lee et al. [3] also examined the effect of including multiple categories of BMI, but found no improved predictive performance over use of a binary variable.

We determined if respondents had memory problems, urinary incontinence, difficulty with various basic or instrumental activities of daily living (e.g., walking across room, bathing, using the telephone, and managing finances), and other functional difficulties (e.g., walking several blocks and climbing stairs). For all functional measures, questions began with "Because of a health problem do you have any difficulty..." We coded responses of "Yes" and "Can't Do" as affirmative and "No" as negative. We encoded as missing those participants who answered "Don't Do" or refused to answer.

We also assessed smoking at baseline, and identified those who participated in vigorous or moderate activity more than once a week.

\section{Statistical analysis}

In order to examine whether control beliefs contributed to 4-year mortality risk after accounting for established biomedical risk factors, we first used 2006 cohort data to: 1) recalibrate the multivariable logistic model reported by Lee et al. [3]; and 2) estimate an enhanced model with control beliefs in addition to all predictors in the Lee et al. model. We provide adjusted odds ratios (OR) and 95\% confidence intervals (CI) for both models. In order to avoid optimistic bias that occurs with evaluation of model performance in the same dataset used for model fitting $[24,29]$, we used 2008 cohort data for external validation of the classic biomedical model and the enhanced model with control beliefs (i.e., evaluated the predictive accuracy of both models in a dataset independent of the one used for fitting the models). We calculated two indicators of overall accuracy: 1) $c$-statistic describes the ability to discriminate between those who have an event and those who do not, and 2) Hosmer-Lemeshow goodness-of-fit $\chi^{2}$ evaluates model calibration or "fit", showing how accurately the model predicts the actual observed risk (non-significant $p$-values of 0.05 or greater indicate adequate fit).

Finally, we also used 2008 cohort data to investigate whether our enhanced risk model improved the classification of individuals into low vs. high-risk groups. We defined "low risk" as $4 \%$ or lower predicted risk; $4 \%$ was the observed mortality reported by Lee et al. [3] for those at or below median risk, and other mortality models have found similar results [30]. We calculated categorical Net Reclassification Improvement (NRI); overall NRI is the sum of event and non-event NRI, which are proportions of individuals appropriately reclassified among those with and without the outcome of interest, respectively [31, 32]. Larger NRI indicates improved classification. We also determined Cohen's kappa statistic and McNemar's $\chi^{2}$, to examine agreement and discrepancy between the 2 models.

To address missing data, we used multiple imputations by chained equations [33] to generate pooled parameter estimates based on 25 imputed datasets, under a missingness at random assumption. Highest missingness was observed for BMI (15\% in 2006 cohort, $12 \%$ in 2008 cohort); all other predictors had 
less than 5\% missingness. Analyses were performed using R v. 3.0.2 and "predictABEL" package [34].

\section{Results}

Baseline characteristics and outcomes for 2006 and 2008 cohorts appear in Table 1. As expected, the 2008 cohort was slightly older (mean age 69.5 years compared to 68.3 years for 2006 cohort), with concomitant small increases in the prevalence of most medical conditions and urinary incontinence. Observed 4-year mortality was nearly $12 \%$ for both cohorts.

\section{Association of control beliefs with 4-year mortality risk} When we refit the classic biomedical risk model for 4-year mortality [3], all risk factors were significantly associated with increased risk (Table 2), except for difficulty with pushing or pulling large objects (OR 1.21, 95\% CI 1.00-1.47). In agreement with Lee et al. [3], highest risks were associated with older age categories (reference 50-59 years), with OR increasing steadily through 85 and older, although the relative increases in risk were slightly lower than those previously reported (Table 2). Factors associated with the next highest levels of increased risk were having heart failure (OR 2.43, 95\% CI 1.81-3.27), difficulty with bathing (OR 2.41, 95\% CI 1.62-2.84), and difficulty with walking several blocks (OR 2.11, 95\% CI 1.752.56; Table 2).

In our enhanced model with control beliefs, we found significantly increased mortality risk associated with higher levels of perceived constraints and lower levels of health-specific control (Table 2). Perceived constraints scores in the third and fourth quartiles were associated with higher risks (OR 1.37, 95\% CI 1.03-1.81 and OR $1.45,95 \%$ CI, 1.09-1.92, respectively), whereas all scores for health-specific control above the first quartile were associated with lower risk (OR 0.69-0.78; Table 2). Perceived mastery scores in the second quartile were associated with decreased risk (OR $0.79,95 \%$ CI $0.62-$ 0.99), but scores in the third and fourth quartiles were not significantly associated with risk for mortality (Table 2). With the addition of control belief variables, the classic biomedical risk factors largely remained significant and of similar risk magnitude, except for difficulty with managing finances, which became nonsignificant (classic biomedical model OR 1.40, 95\% CI 1.02-1.93, and enhanced model with control beliefs OR $1.28,95 \%$ CI 0.93-1.76).

\section{Comparison of classic biomedical and enhanced risk models for 4-year mortality}

We used 2008 cohort data to evaluate predictive accuracy for the classic biomedical and enhanced risk model with control beliefs. We found no difference between the two models in overall performance. For discrimination, $c$-statistics were 0.815 and 0.817 for the classic and enhanced models, respectively. The Hosmer-Lemeshow tests also showed adequate fit for both models $\left(\chi^{2} p\right.$-value $=0.09$ for classic model vs. 0.24 for enhanced model). When we compared low vs. high-risk classification by the two models, we identified significant improvement in reclassification with the enhanced model (categorical NRI 0.026, 95\% CI 0.016-0.036, p-value <0.001). Event NRI was $0.13 \%$, indicating a relatively small proportion of individuals who died were more appropriately classified by the enhanced model. In contrast, non-event NRI was $2.41 \%$, showing that the enhanced model more appropriately classified a larger proportion of people who remained alive during follow-up. Although there was high agreement between the 2 models (Cohen's kappa 0.88), we also found evidence of differential categorization (McNemar's $\chi^{2} p$-value $\left.<0.001\right)$.

More than a quarter of the 2008 cohort were classified as having low risk by both models, while $15.8 \%(n=311)$ of these individuals were differentially categorized by the two models (Table 3). Among individuals who were differentially categorized, those who were identified as low-risk by only the enhanced model were generally older, had higher education status and household incomes, and had higher prevalence of diabetes mellitus and cancer (Table 3). Observed 4-year mortality was lowest $(1.0 \%)$ among those who were predicted to have low risk by both models, followed by $1.8 \%$ for those classified as low-risk by only the enhanced model, and lastly, $5.0 \%$ for individuals identified as low-risk by only the classic model.

\section{Discussion}

Using data from a nationally representative sample of older Americans, we evaluated an enhanced model for 4-year mortality risk that accounted for control beliefs and a set of classic biomedical risk factors [3]. In our enhanced model, high scores for perceived constraints were significantly associated with increased mortality risk, and high scores for health-specific control were associated with decreased risk. The impact of perceived mastery was less clear, with significantly decreased risk only for second quartile scores. Although both classic and enhanced models performed similarly in overall predictive accuracy, we found that inclusion of control beliefs improved classification of individuals into low vs. high-risk groups.

In refitting the classic 4-year mortality risk model by Lee et al. [3], we found similar risks associated with most of the original predictors, although several had smaller magnitudes of increased risks. Our sample was somewhat older (e.g., $23 \%$ of 2006 cohort were $50-59$ and $20 \%$ were $65-69$, compared with $27 \%$ and $15 \%$ for 
Table 1 Baseline characteristics and 4-year mortality for Health and Retirement Study cohorts

\begin{tabular}{|c|c|c|}
\hline Characteristics & $\begin{array}{l}2006 \text { Cohort }^{\mathrm{a}} \\
(n=7313)\end{array}$ & $\begin{array}{l}2008 \text { Cohort }^{\mathrm{a}} \\
(n=6301)\end{array}$ \\
\hline \multicolumn{3}{|l|}{ Sociodemographics, \% (n) } \\
\hline \multicolumn{3}{|l|}{ Age in years: } \\
\hline $50-59$ & $23.1(1692)$ & 19.0 (1198) \\
\hline $60-64$ & $14.0(1027)$ & $12.7(802)$ \\
\hline $65-69$ & $19.6(1432)$ & $19.2(1212)$ \\
\hline $70-74$ & $16.4(1200)$ & $18.6(1174)$ \\
\hline $75-79$ & $12.0(879)$ & $14.1(888)$ \\
\hline $80-84$ & $8.2(601)$ & $8.8(557)$ \\
\hline$\geq 85$ & $6.6(482)$ & $7.5(471)$ \\
\hline Female & $58.3(4260)$ & 59.9 (3773) \\
\hline \multicolumn{3}{|l|}{ Race: } \\
\hline White & $84.4(6175)$ & $84.1(5301)$ \\
\hline Black & $13.1(960)$ & $13.2(833)$ \\
\hline Hispanic & $8.0(586)$ & $9.0(564)$ \\
\hline Married & $64.7(4735)$ & $61.0(3843)$ \\
\hline \multicolumn{3}{|l|}{ Education: } \\
\hline High school degree & $32.3(2362)$ & $31.9(2007)$ \\
\hline College or above & $44.1(3224)$ & $43.5(2743)$ \\
\hline \multicolumn{3}{|l|}{ Total household income ${ }^{b}$ : } \\
\hline $1^{\text {st }}$ quartile & $22.9(1676)$ & $23.4(1477)$ \\
\hline $2^{\text {nd }}$ quartile & $24.6(1800)$ & $26.9(1693)$ \\
\hline $3^{\text {rd }}$ quartile & $25.6(1872)$ & $25.2(1585)$ \\
\hline $4^{\text {th }}$ quartile & $26.9(1965)$ & $24.5(1546)$ \\
\hline \multicolumn{3}{|l|}{ Health conditions, \% (n) } \\
\hline Diabetes mellitus & $20.3(1487)$ & $21.5(1353)$ \\
\hline Hypertension & $57.4(4195)$ & $60.9(3839)$ \\
\hline Heart disease & $25.1(1837)$ & $27.1(1705)$ \\
\hline Heart failure & $3.5(258)$ & $3.8(241)$ \\
\hline Stroke & $6.3(461)$ & $7.4(467)$ \\
\hline Cancer & $15.3(1119)$ & $16.0(1009)$ \\
\hline Lung disease & $10.2(746)$ & $11.7(738)$ \\
\hline Arthritis & $61.2(4479)$ & $64.5(4065)$ \\
\hline Psychiatric problems & $15.9(1162)$ & $17.4(1098)$ \\
\hline Body mass index $<25 \mathrm{~kg} / \mathrm{m}^{2}$ & $21.1(1541)$ & $21.3(1341)$ \\
\hline \multicolumn{3}{|l|}{ Psychological characteristics, mean (SD) } \\
\hline Constraints, range 1-6 & $2.24(1.19)$ & $2.22(1.21)$ \\
\hline Mastery, range 1-6 & $4.75(1.11)$ & $4.77(1.10)$ \\
\hline Health-specific control, range 0-10 & $7.21(2.39)$ & $7.27(2.06)$ \\
\hline \multicolumn{3}{|l|}{ Functional impairments, \% (n) } \\
\hline Problems with memory & $3.0(221)$ & $3.1(195)$ \\
\hline Urinary incontinence & $21.4(1565)$ & $25.4(1599)$ \\
\hline
\end{tabular}

Table 1 Baseline characteristics and 4-year mortality for Health and Retirement Study cohorts (Continued)

\begin{tabular}{|c|c|c|}
\hline \multicolumn{3}{|l|}{ Difficulty with $A D L^{c}$ : } \\
\hline Walking across room & $5.9(434)$ & $6.3(396)$ \\
\hline Bathing & $5.2(378)$ & $5.5(345)$ \\
\hline Dressing & $8.9(652)$ & $8.5(533)$ \\
\hline Eating & $2.4(174)$ & $2.3(142)$ \\
\hline Transferring in or out of bed & $5.3(389)$ & $5.0(316)$ \\
\hline Toileting & $5.4(395)$ & $4.6(287)$ \\
\hline \multicolumn{3}{|l|}{ Difficulty with $I A D L^{c}$ : } \\
\hline Using the telephone & $2.7(199)$ & $2.9(182)$ \\
\hline Managing finances & $4.1(301)$ & $4.0(255)$ \\
\hline Shopping for groceries & $7.7(565)$ & $7.5(471)$ \\
\hline Managing medications & $2.7(195)$ & $2.6(164)$ \\
\hline Preparing meals & $4.5(327)$ & $4.4(277)$ \\
\hline \multicolumn{3}{|l|}{ Other functional difficulties ${ }^{c}$ : } \\
\hline Walking several blocks & $29.7(2174)$ & $30.6(1931)$ \\
\hline Climbing stairs & $43.5(3183)$ & $43.4(2734)$ \\
\hline Pushing or pulling large object & $25.0(1825)$ & $24.0(1515)$ \\
\hline Getting up from chair & $41.5(3032)$ & $41.8(2636)$ \\
\hline \multicolumn{3}{|l|}{ Health behaviors, \% (n) } \\
\hline Vigorous activity more than once per week & $23.0(1680)$ & $23.6(1484)$ \\
\hline Moderate activity more than once per week & $55.8(4078)$ & $53.1(3348)$ \\
\hline Current smoking & $12.8(938)$ & 12.7 (802) \\
\hline \multicolumn{3}{|l|}{ Events, \% (n) } \\
\hline Deaths $^{d}$ & $11.7(856)$ & $11.8(743)$ \\
\hline
\end{tabular}

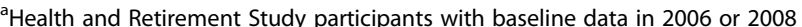
${ }^{b}$ Quartiles assigned based on distribution of incomes from all individuals who responded in 2006 or 2008

${ }^{\mathrm{C}}$ All functional limitations (including $\mathrm{ADL}=$ basic activities of daily living and IADL = instrumental activities of daily living) were defined using questions beginning with "Because of a health problem do you have any difficulty..." Response categories included "Yes" and "Can't Do" (both coded as affirmative), "No" (coded as negative), and "Don't Do" and "Refused" (both coded as missing)

${ }^{d}$ Death by 2011 or 2013, for 2006 or 2008 cohorts, respectively

those age groups reported by Lee et al. [3]). Additionally, Lee et al. [3] used geographic location to select the sample for model development, thus excluding participants from the southern United States; we used nationally representative data at all stages of our analysis.

Our enhanced model separately accounted for specific important biomedical risk factors and demonstrated that perceived constraints and health-specific control were independently associated with meaningful differences in mortality risk. Past studies examining the relationship between control beliefs and mortality assessed health as a single self-reported general rating and/or a count of medical conditions [13-17]; therefore, they failed to adjust for differential risks associated with individual conditions or disabilities [3, 18]. Furthermore, some of this previous work found no significant association 
Table 2 Risk factors for 4-year mortality in multi-variable logistic modeling

\begin{tabular}{|c|c|c|c|c|}
\hline \multirow[t]{2}{*}{ Risk factors } & \multicolumn{2}{|l|}{ Classic model $^{a}$} & \multicolumn{2}{|c|}{ Enhanced model with control beliefs ${ }^{\mathrm{b}}$} \\
\hline & Adjusted OR (95\% Cl) & $p$-value & Adjusted OR (95\% Cl) & $p$-value \\
\hline \multicolumn{5}{|l|}{ Demographics } \\
\hline \multicolumn{5}{|l|}{ Age in years: } \\
\hline $50-59$ & 1 & - & 1 & - \\
\hline $60-64$ & $1.61(1.09-2.36)$ & 0.016 & $1.66(1.13-2.45)$ & 0.010 \\
\hline $65-69$ & $2.57(1.85-3.57)$ & $<0.001$ & $2.68(1.92-3.73)$ & $<0.001$ \\
\hline $70-74$ & $3.10(2.22-4.34)$ & $<0.001$ & $3.22(2.30-4.50)$ & $<0.001$ \\
\hline $75-79$ & $4.44(3.17-6.21)$ & $<0.001$ & $4.64(3.31-6.51)$ & $<0.001$ \\
\hline $80-84$ & $6.65(4.71-9.39)$ & $<0.001$ & $6.74(4.76-9.53)$ & $<0.001$ \\
\hline$\geq 85$ & $14.4(10.2-20.4)$ & $<0.001$ & $14.5(10.2-20.5)$ & $<0.001$ \\
\hline Male & $1.84(1.56-2.17)$ & $<0.001$ & $1.85(1.57-2.18)$ & $<0.001$ \\
\hline \multicolumn{5}{|l|}{ Health conditions \& behaviors } \\
\hline Diabetes mellitus & $1.64(1.37-1.97)$ & $<0.001$ & $1.63(1.36-1.97)$ & $<0.001$ \\
\hline Heart failure & $2.43(1.81-3.27)$ & $<0.001$ & $2.37(1.76-3.19)$ & $<0.001$ \\
\hline Cancer & $1.54(1.27-1.86)$ & $<0.001$ & $1.52(1.26-1.84)$ & $<0.001$ \\
\hline Lung disease & $1.61(1.29-2.00)$ & $<0.001$ & $1.58(1.27-1.97)$ & $<0.001$ \\
\hline $\mathrm{BMl}<25 \mathrm{~kg} / \mathrm{m}^{2}$ & $1.69(1.40-2.05)$ & $<0.001$ & $1.70(1.41-2.06)$ & $<0.001$ \\
\hline Current smoker & $1.89(1.50-2.39)$ & $<0.001$ & $1.83(1.45-2.31)$ & $<0.001$ \\
\hline \multicolumn{5}{|l|}{ Functional impairments } \\
\hline Bathing & $2.14(1.62-2.84)$ & $<0.001$ & $2.00(1.51-2.64)$ & $<0.001$ \\
\hline Managing finances & $1.40(1.02-1.93)$ & 0.035 & $1.28(0.93-1.76)$ & 0.136 \\
\hline Walking several blocks & $2.11(1.75-2.56)$ & $<0.001$ & $1.97(1.62-2.39)$ & $<0.001$ \\
\hline Push/pulling large object & $1.21(1.00-1.47)$ & 0.056 & $1.12(0.92-1.37)$ & 0.252 \\
\hline \multicolumn{5}{|l|}{ Control beliefs } \\
\hline \multicolumn{5}{|l|}{ Perceived constraints ${ }^{c}:$} \\
\hline $1^{\text {st }}$ Quartile & - & - & 1 & - \\
\hline $2^{\text {nd }}$ Quartile & - & - & $1.14(0.86-1.51)$ & 0.365 \\
\hline $3^{\text {rd }}$ Quartile & - & - & $1.37(1.03-1.81)$ & 0.029 \\
\hline $4^{\text {th }}$ Quartile & - & - & $1.45(1.09-1.92)$ & 0.010 \\
\hline \multicolumn{5}{|l|}{ Perceived masteryc: } \\
\hline $1^{\text {st }}$ Quartile & - & - & 1 & - \\
\hline $2^{\text {nd }}$ Quartile & - & - & $0.79(0.62-0.99)$ & 0.039 \\
\hline $3^{\text {rd }}$ Quartile & - & - & $0.86(0.68-1.09)$ & 0.200 \\
\hline $4^{\text {th }}$ Quartile & - & - & $0.95(0.74-1.22)$ & 0.691 \\
\hline \multicolumn{5}{|l|}{ Health-specific control': } \\
\hline $1^{\text {st }}$ Quartile & - & - & 1 & - \\
\hline $2^{\text {nd }}$ Quartile & - & - & $0.72(0.57-0.91)$ & 0.006 \\
\hline $3^{\text {rd }}$ Quartile & - & - & $0.69(0.54-0.89)$ & 0.004 \\
\hline $4^{\text {th }}$ Quartile & - & - & $0.78(0.61-0.99)$ & 0.010 \\
\hline
\end{tabular}

$\mathrm{OR}=$ odds ratio; $95 \% \mathrm{Cl}=95 \%$ confidence interval; $\mathrm{BMI}=$ body mass index

ancludes all risk factors from model developed by Lee et al. [3]

${ }^{b}$ Includes all risk factors from model developed by Lee et al. [3] and 3 control belief variables (perceived constraints, perceived mastery, and health-specific control)

'Scores divided into quartiles, see Methods 
Table 3 Characteristics of individuals with low predicted 4-year mortality risk by classic vs. enhanced models

\begin{tabular}{|c|c|c|c|c|}
\hline & \multicolumn{3}{|l|}{ Low risk ${ }^{a}$} & \multirow{2}{*}{$\begin{array}{l}\text { Not low risk } \\
(n=4327)\end{array}$} \\
\hline & $\begin{array}{l}\text { Both models } \\
(n=1663)\end{array}$ & $\begin{array}{l}\text { Only classic model } \\
(n=89)\end{array}$ & $\begin{array}{l}\text { Only enhanced model } \\
(n=222)\end{array}$ & \\
\hline \multicolumn{5}{|l|}{ Predicted risk, mean (SD) } \\
\hline Classic Model $^{\mathrm{b}}$ & $2.3(0.8)$ & $3.5(0.3)$ & $4.7(0.4)$ & $17.0(15.0)$ \\
\hline Enhanced Model ${ }^{c}$ & $2.2(0.8)$ & $4.6(0.5)$ & $3.6(0.3)$ & $17.1(15.3)$ \\
\hline Observed deaths, \% (n) & $1.0(17)$ & $5.0(5)$ & $1.8(4)$ & $16.6(717)$ \\
\hline \multicolumn{5}{|l|}{ Sociodemographics, \% (n) } \\
\hline \multicolumn{5}{|l|}{ Age in years: } \\
\hline $50-59$ & $55.2(918)$ & $33.7(30)$ & $12.2(27)$ & $5.2(223)$ \\
\hline $60-64$ & $23.1(384)$ & $33.7(30)$ & $22.1(49)$ & $7.8(339)$ \\
\hline $65-69$ & $12.9(214)$ & $7.9(7)$ & $51.4(114)$ & $20.3(877)$ \\
\hline $70-74$ & $8.8(147)$ & $24.7(22)$ & $5.4(12)$ & $22.9(993)$ \\
\hline $75-79$ & $0(0)$ & $0(0)$ & $9.0(20)$ & $20.1(868)$ \\
\hline $80-84$ & $0(0)$ & $0(0)$ & $0(0)$ & $12.8(556)$ \\
\hline$\geq 85$ & $0(0)$ & $0(0)$ & $0(0)$ & $10.9(461)$ \\
\hline Female & $76.8(1278)$ & $65.2(58)$ & $68.0(151)$ & $52.8(2286)$ \\
\hline \multicolumn{5}{|l|}{ Race: } \\
\hline White & $82.3(1369)$ & $85.4(76)$ & $85.6(190)$ & $84.7(3666)$ \\
\hline Black & $13.5(225)$ & $7.9(7)$ & $13.5(30)$ & $13.2(571)$ \\
\hline Other & $4.1(69)$ & $6.7(6)$ & $0.9(2)$ & $2.1(90)$ \\
\hline Hispanic & $11.7(195)$ & $16.9(15)$ & $6.8(15)$ & $7.8(339)$ \\
\hline Married & $70.2(1168)$ & $61.8(55)$ & $64.0(142)$ & $56.4(2440)$ \\
\hline \multicolumn{5}{|l|}{ Education: } \\
\hline High school degree & $29.8(496)$ & $32.6(29)$ & $28.8(64)$ & $32.8(1418)$ \\
\hline College or above & $55.7(926)$ & $37.1(33)$ & $54.5(121)$ & $38.4(1663)$ \\
\hline \multicolumn{5}{|c|}{ Total household income ${ }^{d}$ : } \\
\hline $1^{\text {st }}$ quartile & $12.6(210)$ & $22.5(20)$ & $16.2(36)$ & $28.0(1211)$ \\
\hline $2^{\text {nd }}$ quartile & $18.3(304)$ & $28.1(25)$ & $27.9(62)$ & $30.1(1302)$ \\
\hline $3^{\text {rd }}$ quartile & $27.6(459)$ & $22.5(20)$ & $20.7(46)$ & $24.5(1060)$ \\
\hline $4^{\text {th }}$ quartile & $41.5(690)$ & $27.0(24)$ & $35.1(78)$ & $17.4(754)$ \\
\hline Has health insurance & $90.5(1505)$ & $88.8(79)$ & $95.9(213)$ & $97.8(4231)$ \\
\hline \multicolumn{5}{|l|}{ Health conditions, \% (n) } \\
\hline Diabetes mellitus & $6.9(115)$ & $9.0(8)$ & $18.9(42)$ & $27.5(1188)$ \\
\hline Hypertension & $46.8(778)$ & $58.4(52)$ & $57.7(128)$ & $66.6(2881)$ \\
\hline Heart disease & $10.3(171)$ & $18.0(16)$ & $20.7(46)$ & $34.0(1472)$ \\
\hline Heart failure & $0(0)$ & $0(0)$ & $0(0)$ & $5.6(241)$ \\
\hline Stroke & $2.0(33)$ & $2.2(2)$ & $2.7(6)$ & $8.9(386)$ \\
\hline Cancer & $4.3(71)$ & $3.4(3)$ & $17.6(39)$ & 20.7 (895) \\
\hline Lung disease & $1.4(24)$ & $10.1(9)$ & $5.9(13)$ & $16.0(692)$ \\
\hline Arthritis & $50.4(838)$ & $62.9(56)$ & $65.8(146)$ & $69.9(3025)$ \\
\hline Psychiatric problems & $16.5(16.5)$ & $24.7(22)$ & $14.9(33)$ & $17.7(768)$ \\
\hline $\mathrm{BMI}<25 \mathrm{~kg} / \mathrm{m}^{2}$ & $12.5(208)$ & $12.4(11)$ & $18.9(42)$ & $25.0(1080)$ \\
\hline
\end{tabular}


Table 3 Characteristics of individuals with low predicted 4-year mortality risk by classic vs. enhanced models (Continued)

\begin{tabular}{|c|c|c|c|c|}
\hline \multicolumn{5}{|l|}{ Functional impairments, n (\%) } \\
\hline Problems with memory & $1.1(18)$ & $0(0)$ & $0.5(1)$ & $4.1(176)$ \\
\hline Urinary incontinence & $21.3(354)$ & $27.0(24)$ & $20.7(46)$ & $27.2(1175)$ \\
\hline \multicolumn{5}{|l|}{ Difficulty with ADL: } \\
\hline Walking across room & $0.5(8)$ & $0(0)$ & $0.5(1)$ & $8.9(387)$ \\
\hline Bathing & $0(0)$ & $0(0)$ & $0(0)$ & $8.0(345)$ \\
\hline Dressing & $1.7(28)$ & $5.6(5)$ & $1.4(3)$ & $11.5(497)$ \\
\hline Eating & $0(0)$ & $0(0)$ & $0.5(1)$ & $3.3(141)$ \\
\hline Transferring in or out of bed & $1.1(19)$ & $4.5(4)$ & $3.2(7)$ & $6.6(286)$ \\
\hline Toileting & $0.7(11)$ & $2.2(2)$ & $0.9(2)$ & $6.3(272)$ \\
\hline \multicolumn{5}{|l|}{ Difficulty with IADL: } \\
\hline Using the telephone & $0.4(6)$ & $3.4(3)$ & $0(0)$ & $4.0(171)$ \\
\hline Managing finances & $0.5(8)$ & $1.1(1)$ & $1.4(3)$ & $5.6(243)$ \\
\hline Shopping for groceries & $0.7(12)$ & $3.4(3)$ & $1.8(4)$ & $10.4(452)$ \\
\hline Managing medications & $0.6(10)$ & $4.5(4)$ & $0.9(2)$ & $3.4(148)$ \\
\hline Preparing meals & $0.2(3)$ & $2.2(2)$ & $0.9(2)$ & $6.2(270)$ \\
\hline \multicolumn{5}{|l|}{ Other functional difficulties: } \\
\hline Walking several blocks & $3.8(63)$ & $13.5(12)$ & $15.3(34)$ & $42.1(1822)$ \\
\hline Climbing stairs & $29.3(487)$ & $42.7(38)$ & $27.9(62)$ & $47.4(2049)$ \\
\hline Push or pull large object & $27.0(449)$ & $41.6(37)$ & $34.2(76)$ & $50.2(2172)$ \\
\hline Getting up from chair & $10.8(180)$ & $23.6(21)$ & $12.2(27)$ & $29.7(1287)$ \\
\hline \multicolumn{5}{|l|}{ Health behaviors, \% (n) } \\
\hline Vigorous activity $^{\mathrm{e}}$ & $29.2(485)$ & $13.5(12)$ & $23.0(51)$ & $17.2(743)$ \\
\hline Moderate activity ${ }^{\mathrm{e}}$ & $53.2(884)$ & $42.7(38)$ & $53.2(118)$ & $37.3(1614)$ \\
\hline Current smoker & 7.5 (124) & $16.9(15)$ & $9.9(22)$ & $14.8(641)$ \\
\hline
\end{tabular}

$A D L=$ basic activities of daily living, $I A D L=$ instrumental activities of daily living, $S D=$ standard deviation, $B M I=$ body mass index

${ }^{a}$ Defined as predicted 4-year mortality risk of $4 \%$ or less

bIncludes all risk factors from model developed by Lee et al. [3]

'Includes all risk factors from model developed by Lee et al. [3], and control belief variables in quartiles (perceived constraints, perceived mastery, and health-specific control)

${ }^{d}$ Quartiles based on distribution of incomes from all individuals who responded in 2008

e Level of activity as specified, occurring more than once a week

between control beliefs and mortality, when general measures of health were incorporated into risk models $[15,16]$. Thus, our results contribute to the evidence supporting the importance of control beliefs for mortality risk.

It is unclear why perceived mastery was not as important for mortality risk in our analysis. Past studies have suggested that "positive" beliefs may be less relevant than "negative" control perceptions for health and physical function $[9,26,35]$. Possibly, respondents may be more accurate in their assessments of constraints compared with mastery, particularly with respect to socioeconomic factors. Or, perceived constraints may have greater impact on health-related behaviors or physiologic pathways. Further work will be required to understand the relative roles and consequences of positive vs. negative control beliefs, as well as global vs. health-specific perceptions.
Accounting for control beliefs may be especially important for predicting mortality risk in older individuals who have one or more serious medical diagnoses. Our enhanced model differentially classified $3.5 \%$ of individuals as low-risk; the observed mortality in this group was less than $2 \%$, well below our $4 \%$ threshold for low risk. In this group, $65.8 \%$ were 65 or older, while nearly a fifth had diabetes and $17.6 \%$ had cancer diagnoses $[5,6]$. In contrast, those classified as low-risk by only the classic model had an observed mortality of $5 \%$, and comparatively, had lower income and education status. Socioeconomic factors, such as education, perceived social status, and perceived discrimination, have been associated with variation in control beliefs $[9-11,17]$. Some have found that control beliefs may moderate the impact of educational status [17], while others have reported that perceived control may mediate the relationship between socioeconomic status and health 
outcomes [36]. Thus, future work is needed to better understand the interplay between control beliefs and socioeconomic factors, and whether the impact of control beliefs in our enhanced model may be due, in part, to known relationships between socioeconomic factors and health.

Our results indicate that accounting for control beliefs could improve risk stratification of older adults. Mortality risk models are being increasingly used for diverse purposes, including selection of appropriate preventative services [37, 38] and adjusting goals for chronic disease management [39]. For example, routine colorectal cancer screening is not recommended for adults aged $76-85$ [40], but some in this age range may have low mortality risk and thus, have time to benefit from continued screening [41]. Additionally, we may be able to address disparities in general control beliefs with targeted services and support, particularly for disadvantaged groups. Control beliefs reflect diverse psychosocial factors, including dispositional traits, socioeconomic characteristics, and life experiences, offering us an important opportunity to integrate diverse patient factors and improve personalization of clinical care.

There are some limitations to our study. Logistic regression does not readily account for the length of exposure to risk factors, and estimates from such models may diverge from those using survival analyses, such as Cox proportional hazards functions, over a longer period of follow-up, for more frequent outcomes, and/or with substantial censoring (e.g., due to incomplete follow-up) [23]. In our study, mortality was uncommon within the 4-year timeframe and follow-up was excellent; thus, logistic modeling is likely comparable to survival methods in estimating mortality risk for this period. We used self-reported data for health conditions and functional impairments; self-reported health information generally correspond well with data from medical records, but may be biased towards under-reporting [42, 43]. Depressive symptoms were not examined in the current analyses because depressive symptoms were not included as predictors in the original biomedical model validated by Lee et al. [3] In previous work, we found low baseline prevalence of depressive symptoms in the HRS cohort and no significant relationship between these symptoms and risk for poor health outcomes [44]; however, depressive symptoms may be an important area for future study in other samples. We also did not determine the influence of other individual conditions or specific combinations of medical diagnoses; these may be important to explore in future work. The HRS cohort also has high education status and low functional impairments; thus, our results may not be generalizable to those with poorer mental health, lower education, and/or greater impairments. Finally, in this non-experimental study, there remains the possibility of unmeasured confounders contributing to associations between control beliefs and mortality risk.

\section{Conclusions}

In summary, our results indicate that control beliefs are important for predicting mortality risk in older adults. Moreover, control beliefs may account for risks derived from diverse psychosocial sources and enable implementation of targeted interventions. Future work is needed to determine how assessment of control beliefs may be incorporated into clinical care and whether we can better support those at increased risk due to high perceived constraints and/or low health-specific control.

\section{Abbreviations}

95\% Cl: 95\% Confidence Interval; BMI: Body mass index; HRS: Health and retirement study; NRI: Net reclassification improvement; OR: Odds ratio

\section{Acknowledgments}

None

\section{Funding}

Support for Wei Duan-Porter was provided by Grant No. TPH 21-024 from the Department of Veterans Affairs Office of Academic Affiliations. Publication support was provided by the Durham VA Health Services Research Center of Innovation funding (CIN 13-410). The sponsors had no role in the design, collection, analysis, interpretation of data, or preparation of the manuscript. The views expressed in this article are those of the authors and do not necessarily reflect the position or policy of the Department of Veterans Affairs or the United States government.

Availability of data and materials

HRS data are publicly available at http://hrsonline.isr.umich.edu/.

\section{Authors' contributions}

WDP, MD, PhD - study concept and design, analysis and interpretation of data, statistical analysis, drafting of manuscript and critical revisions for important intellectual content. SNH, MD, MHSc - study concept and design, analysis and interpretation of data, and critical revisions for important intellectual content. BN, PhD — study concept and design, statistical analysis and critical revisions for important intellectual content. $\mathrm{CVH}, \mathrm{MSc}$,

$\mathrm{PhD}$ —study concept and design, analysis and interpretation of data, critical revisions for important intellectual content, and supervision of study. All authors read and approved the final manuscript.

\section{Competing interests}

The authors declare that they have no competing interests.

\section{Consent for publication}

Not applicable.

\section{Ethics approval and consent to participate}

HRS participants provided informed consent at the time of enrollment. Our analyses utilizing HRS data were approved by the Durham Veterans Affairs Medical Center Institutional Review Board.

\section{Author details}

${ }^{1}$ Minneapolis VA Health Services Research and Development, One Veterans Dr, Minneapolis, MN 55417, USA. ²Durham VA Health Services Research and Development, Durham, NC, USA. ${ }^{3}$ Durham VA Geriatrics Resarch, Education, and Clinical Center, Durham, NC, USA. ${ }^{4}$ Department of Medicine, Division of Geriatrics, Duke University School of Medicine, Durham, NC, USA. ${ }^{5}$ Duke University Center for the Study of Aging and Human Development, Durham, NC, USA. ${ }^{6}$ Department of Public Health Sciences,Medical University of South Carolina, Charleston, SC, USA. 
Received: 12 January 2016 Accepted: 6 December 2016

\section{Published online: 11 January 2017}

\section{References}

1. Berkman LF, Seeman TE, Albert M, Blazer D, Kahn R, Mohs R, et al. High, usual and impaired functioning in community-dwelling older men and women: findings from the MacArthur Foundation Research Network on Successful Aging. J Clin Epidemiol. 1993;46:1129-40.

2. $\quad$ Depp CA, Jeste DV. Definitions and predictors of successful aging: a comprehensive review of larger quantitative studies. Am J Geriatr Psychiatry. 2006;14:6-20.

3. Lee SJ, Lindquist K, Segal MR, Covinsky KE. Development and validation of a prognostic index for 4-year mortality in older adults. JAMA. 2006;295:801-8.

4. Lee PG, Cigolle C, Blaum C. The co-occurrence of chronic diseases and geriatric syndromes: the Health and Retirement Study. J Am Geriatr Soc. 2009;57:511-6

5. Gherman A, Schnur J, Montgomery G, Sassu R, Veresiu I, David D. How are adherent people more likely to think? A meta-analysis of health beliefs and diabetes self-care. Diabetes Educ. 2011;37:392-408.

6. Celano CM, Beale EE, Moore SV, Wexler DJ, Huffman JC. Positive psychological characteristics in diabetes: a review. Curr Diab Rep. 2013;13:917-29.

7. Lachman ME. Perceived Control Over Aging-Related Declines Adaptive Beliefs and Behaviors. Curr Dir Psychol Sci. 2006;15:282-6.

8. Skinner EA. A guide to constructs of control. J Pers Soc Psychol. 1996:71:549-70.

9. Lachman ME, Weaver SL. The sense of control as a moderator of social class differences in health and well-being. J Pers Soc Psychol. 1998;74:763-73.

10. Pearlin LI, Nguyen KB, Schieman S, Milkie MA. The life-course origins of mastery among older people. J Health Soc Behav. 2007;48:164-79.

11. Mirowsky J, Ross CE. Life Course Trajectories of Perceived Control and Their Relationship to Education. Am J Sociol. 2007;112:1339-82.

12. McEwen BS. Protective and damaging effects of stress mediators. N Engl J Med. 1998;338:171-9.

13. Menec VH, Chipperfield JG. The interactive effect of perceived control and functional status on health and mortality among young-old and old-old adults. J Gerontol B Psychol Sci Soc Sci. 1997;52:P118-26.

14. Infurna FJ, Gerstorf D, Ram N, Schupp J, Wagner GG. Long-term antecedents and outcomes of perceived control. Psychol Aging. 2011;26:559-75

15. Infurna FJ, Ram N, Gerstorf D. Level and change in perceived control predict 19-year mortality: findings from the Americans' changing lives study. Dev Psychol. 2013;49:1833-47.

16. Wiest M, Schüz B, Wurm S. Life satisfaction and feeling in control: indicators of successful aging predict mortality in old age. J Health Psychol. 2013;18:1199-208.

17. Turiano NA, Chapman BP, Agrigoroaei S, Infurna FJ, Lachman M. Perceived control reduces mortality risk at low, not high, education levels. Health Psychol. 2014;33:883-90.

18. Carey EC, Walter LC, Lindquist K, Covinsky KE. Development and validation of a functional morbidity index to predict mortality in community-dwelling elders. J Gen Intern Med. 2004;19:1027-33.

19. Fortin M, Hudon C, Dubois M-F, Almirall J, Lapointe L, Soubhi $H$ Comparative assessment of three different indices of multimorbidity for studies on health-related quality of life. Health Qual Life Outcomes. 2005;3:74

20. Smith J, Fisher G, Ryan L, Clarke P, House J, Weir DR. Psychosocial and Lifestyle Questionnaire 2006-2010: Documentation Report. Ann Arbor: Survey Research Center, University of Michigan; 2013.

21. Growing Older in America. The Health and Retirement Study | National Institute on Aging [Internet]. 2015. Available from: http://www.nia.nih.gov/ health/publication/growing-older-america-health-and-retirement-study. Cited 19 Oct 2015

22. Sonnega A, Faul JD, Ofstedal MB, Langa KM, Phillips JWR, Weir DR. Cohort Profile: the Health and Retirement Study (HRS). Int J Epidemiol. 2014;43:576-85.

23. Green MS, Symons MJ. A comparison of the logistic risk function and the proportional hazards model in prospective epidemiologic studies. J Chronic Dis. 1983:36:715-23.

24. Bleeker SE, Moll HA, Steyerberg EW, Donders ART, Derksen-Lubsen G, Grobbee DE, et al. External validation is necessary in prediction research: a clinical example. J Clin Epidemiol. 2003;56:826-32.
25. Cruz M, Covinsky K, Widera EW, Stijacic-Cenzer I, Lee SJ. Predicting 10-year mortality for older adults. JAMA. 2013;309:874-6.

26. Infurna FJ, Mayer A. The effects of constraints and mastery on mental and physical health: Conceptual and methodological considerations. Psychol Aging. 2015;30:432-48.

27. Ward MM. Sense of control and sociodemographic differences in selfreported health in older adults. Qual Life Res. 2012;21:1509-18.

28. Ward MM. Sense of Control and Self-Reported Health in a Population-Based Sample of Older Americans: Assessment of Potential Confounding by Affect, Personality, and Social Support. Int J Behav Med. 2013;20:140-7.

29. Steyerberg EW, Bleeker SE, Moll HA, Grobbee DE, Moons KGM. Internal and external validation of predictive models: a simulation study of bias and precision in small samples. J Clin Epidemiol. 2003;56:441-7.

30. Fried LP, Kronmal RA, Newman AB, Bild DE, Mittelmark MB, Polak JF, et al. Risk factors for 5-year mortality in older adults: the Cardiovascular Health Study. JAMA. 1998;279:585-92.

31. Steyerberg EW, Vickers AJ, Cook NR, Gerds T, Gonen M, Obuchowski N, et al. Assessing the performance of prediction models: a framework for traditional and novel measures. Epidemiology. 2010;21:128-38.

32. Leening MJG, Vedder MM, Witteman JCM, Pencina MJ, Steyerberg EW. Net reclassification improvement: computation, interpretation, and controversies: a literature review and clinician's guide. Ann Intern Med. 2014;160:122-31.

33. van Buuren S, Groothuis-Oudshoom K. MICE: Multivariate Imputation by Chained Equations in R. J Stat Softw. 2011;45:1-67.

34. Kundu S, Aulchenko YS, van Duijn CM, Janssens ACJW. PredictABEL: an R package for the assessment of risk prediction models. Eur J Epidemiol. 2011;26:261-4.

35. Surgenor LJ, Horn J, Hudson SM, Lunt H, Tennent J. Metabolic control and psychological sense of control in women with diabetes mellitus. Alternative considerations of the relationship. J Psychosom Res. 2000;49:267-73.

36. Bailis DS, Segall A, Mahon MJ, Chipperfield JG, Dunn EM. Perceived control in relation to socioeconomic and behavioral resources for health. Soc Sci Med. 2001;52:1661-76.

37. Lee SJ, Leipzig RM, Walter LC. Incorporating lag time to benefit into prevention decisions for older adults. JAMA. 2013;310:2609-10.

38. Gross CP. Cancer screening in older persons: a new age of wonder. JAMA Intern Med. 2014;174:1565-7.

39. ADA Standards of Medical Care in Diabetes: 10. Older Adults. Dia Care. 2015;38:S67-9.

40. Colorectal Cancer Screening Recommendation Summary - US Preventive Services Task Force [Internet]. 2008. Available from: http://www. uspreventiveservicestaskforce.org/Page/Topic/recommendation-summary/ colorectal-cancer-screening. Cited 28 May 2015.

41. Lee SJ, Boscardin WJ, Stijacic-Cenzer I, Conell-Price J, O'Brien S, Walter LC. Time lag to benefit after screening for breast and colorectal cancer: metaanalysis of survival data from the United States, Sweden, United Kingdom, and Denmark. BMJ. 2013;346:e8441.

42. Harlow SD, Linet MS. Agreement between questionnaire data and medical records. The evidence for accuracy of recall. Am J Epidemiol. 1989:129:233-48.

43. Okura Y, Urban LH, Mahoney DW, Jacobsen SJ, Rodeheffer RJ. Agreement between self-report questionnaires and medical record data was substantial for diabetes, hypertension, myocardial infarction and stroke but not for heart failure. J Clin Epidemiol. 2004;57:1096-103.

44. Duan-Porter W, Hastings SN, Neelon B, Van Houtven CH. Control Beliefs and Risk for Death, Stroke and Myocardial Infarction in Middle-aged and Older Adults: An Observational Study. J Gen Intern Med. 2015;30:1156-63. 